\title{
Ultrafiltration and Alumina Adsorption of Micelles for the Preconcentration of Copper(II) in Water
}

\author{
Masataka HIRAIDE ${ }^{\dagger}$ and Tsuyoshi ITOH \\ Department of Molecular Design and Engineering, Graduate School of Engineering, Nagoya University, \\ Chikusa, Nagoya 464-8603, Japan
}

\begin{abstract}
Micellar-enhanced ultrafiltration was considered from the viewpoint of trace analysis, by taking copper(II) as an example. Copper(II) cations were collected electrostatically on micelles of sodium dodecyl sulfate, and separated from the mother liquor by ultrafiltration. However, the final solution contained a large amount of surfactant, which caused serious interference in the determination. This problem was overcome by using alumina adsorption, where negatively charged micelles were adsorbed on positively charged alumina particles and then recovered by conventional filtration. The copper was leached from the micelles with $4 \mathrm{~mol} \mathrm{l}^{-1}$ nitric acid, leaving the surfactant on the alumina. The proposed method was successfully applied to an analysis of certified reference water samples.
\end{abstract}

(Received September 30, 2003; Accepted October 28, 2003)

\section{Introduction}

Although modern instrumental methods for trace analysis are highly sensitive and selective, preconcentration techniques are often required to improve the accuracy and precision of the analytical results. ${ }^{1,2}$ Micellar-enhanced ultrafiltration (MEUF) offers a simple separation method, where a surfactant is added to an aqueous solution and forms aggregates, called micelles, into which the desired substance solubilizes. The aqueous solution is then forced through an ultrafiltration membrane with pore sizes small enough to reject the micelles containing the desired substance. This process has been studied for the removal of organic pollutants and heavy metal ions from water. $^{3-7}$ To the best of our knowledge, however, MEUF has not been used for the preconcentration of trace metals at $\mathrm{ng} \mathrm{ml}^{-1}$ levels before the instrumental determination steps.

The present communication describes the limitations of MEUF for the use of preconcentrating trace elements. For example, a relatively large concentration of surfactant seriously disturbed the determination of copper. As an alternative to ultrafiltration, we proposed alumina adsorption, which facilitated a rapid separation of micelles from the mother liquor and eliminated interference from the surfactant. Further, copper was preliminarily converted into the water-insoluble complex with the aid of ammonium pyrrolidinedithiocarbamate (APDC) to widen the scope of the applicability. The proposed method was combined with graphite-furnace atomic absorption spectrometry (GFAAS), which allowed a rapid and reliable determination of traces of copper in river and seawater.

\footnotetext{
$\dagger$ To whom correspondence should be addressed

E-mail: hiraide@numse.nagoya-u.ac.jp
}

\section{Experimental}

\section{Apparatus and reagents}

A Seiko SAS-760 atomic absorption spectrometer equipped with an SAS-715 graphite-furnace atomizer was employed for the determination of copper under the following furnace operating conditions. The graphite tube was gradually warmed during $20 \mathrm{~s}$ to $150^{\circ} \mathrm{C}$ and held for $15 \mathrm{~s}$. The tube was then heated during $5 \mathrm{~s}$ to $800^{\circ} \mathrm{C}$ and held for $10 \mathrm{~s}$; it was further heated to a final atomization temperature of $2400^{\circ} \mathrm{C}$ for $2 \mathrm{~s}$. The clean-up step was performed at $2550^{\circ} \mathrm{C}$ for $3 \mathrm{~s}$ to eliminate the memory effect. The wavelength and hollow-cathode lamp current used were $324.8 \mathrm{~nm}$ and $10 \mathrm{~mA}$, respectively. A Hitachi ECV-843 BY clean bench was used for preconcentration procedures.

An Advantec UHP-43 batch-stirred cell (capacity $70 \mathrm{ml}$ ) was used for ultrafiltration experiments. The membrane filters (43 mm diam.) used were Advantec UK-10 (10000 Da molecular weight cut-off), Diaflo YM-1 (1000 Da) and Diaflo YM-05 $(500 \mathrm{Da})$. An SDS solution $\left(40 \mathrm{mg} \mathrm{ml}^{-1}\right)$ was prepared by dissolving sodium dodecyl sulfate (special grade for water analysis, Nacalai Tesque) in water. An APDC solution $(2.0 \mathrm{mg}$ $\mathrm{ml}^{-1}$ ) was prepared by dissolving ammonium pyrrolidinedithiocarbamate (special grade for AAS, Nacalai Tesque) in water. Alumina particles $(\mathrm{ca} .50 \mu \mathrm{m}$, gamma-type, chromatographic grade, Katayama Chemicals) were washed with $4 \mathrm{~mol} \mathrm{l}^{-1}$ nitric acid for 10 min in a Branson ultrasonic cleaning bath $(42 \mathrm{kHz}$, $120 \mathrm{~W})$ and then rinsed thoroughly with water. Certified reference water samples (SLRS-3, CASS-3 and NASS-5) were obtained from National Research Council of Canada. All reagents used were of analytical grade (Nacalai Tesque), unless stated otherwise. Water was purified by distillation and ion exchange and then passed through a Millipore Milli-Q purification system.

\section{Recommended procedure}

To $100 \mathrm{ml}$ of water sample (preliminarily adjusted to $\mathrm{pH} 2$ ) 


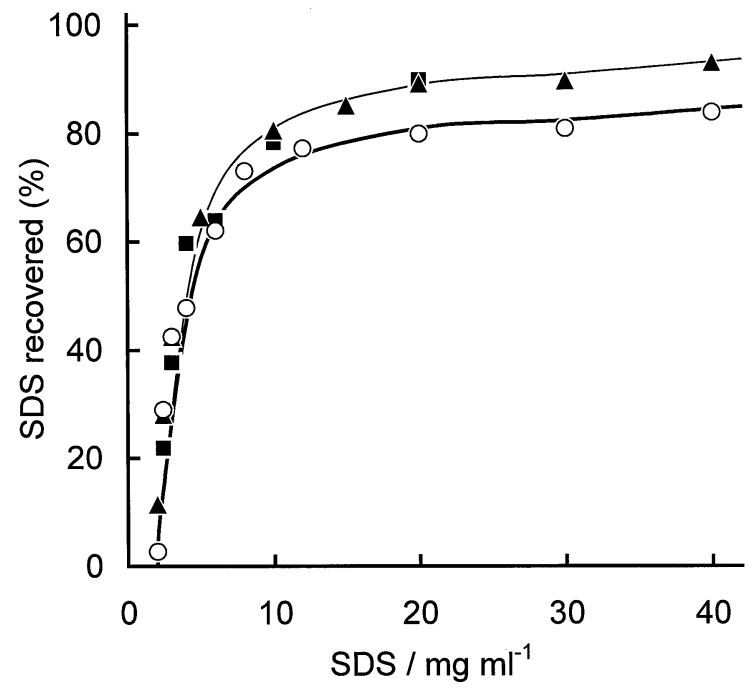

Fig. 1 Effect of the concentration of SDS on ultrafiltration with a 10000-Da ( o), 1000-Da ( $\mathbf{\Delta}$, or 500-Da ( $\mathbf{a})$ membrane filter.

was added $2 \mathrm{ml}$ of an APDC solution to form a copper-APDC complex. After adding $10 \mathrm{ml}$ of an SDS solution, the mixture was stirred for $15 \mathrm{~min}$ to collect the hydrophobic complex in SDS micelles. After adding $3 \mathrm{~g}$ of alumina, the suspension was stirred for $5 \mathrm{~min}$ and then poured into an empty polypropylene column (with a porous polyethylene disk of $36 \mu \mathrm{m}$ pore, $7 \mathrm{~mm}$ in diam.) to separate the micelle-alumina particles from the mother liquor. The copper was desorbed from the micelles with $1 \mathrm{ml}$ of $4 \mathrm{~mol} \mathrm{l}^{-1}$ nitric acid and collected in a 5-ml volumetric flask by suction. The desorption was repeated twice more with $1 \mathrm{ml}$ each of $4 \mathrm{~mol} \mathrm{l}^{-1}$ nitric acid. The combined eluents were diluted to the mark with water. A $10-\mu$ l aliquot of the solution was injected into a graphite cuvette and analyzed by GFAAS. A calibration graph was prepared by taking nanogram quantities of copper and $3 \mathrm{ml}$ of $4 \mathrm{~mol} \mathrm{l}^{-1}$ nitric acid in a 5 -ml volumetric flask and diluting to the mark with water.

\section{Results and Discussion}

\section{Ultrafiltration of micelles collecting copper(II)}

The ultrafiltration cell was initially filled with $20 \mathrm{ml}$ of water containing different amounts of SDS. The permeate solution was analyzed for SDS by the toluidine blue titration method. ${ }^{8}$ Figure 1 shows that the recovery of SDS (the fraction retained on the membrane) increased abruptly above the critical micelle concentration $\left(2.3 \mathrm{mg} \mathrm{ml}^{-1}\right)$ and reached values of $80-90 \%$. Most of the permeable fraction may correspond to monomeric or unassociated surfactant. Among the different membrane filters used here, a 10000-Da cut-off membrane filter was most convenient because filtration was completed within $30 \mathrm{~min}$. With a membrane filter having a 500 or $1000 \mathrm{Da}$ molecular weight cut-off, the filtration required more than $2 \mathrm{~h}$ to treat 20 $\mathrm{ml}$ of the sample solution.

The collection efficiency was examined using $20 \mathrm{ml}$ of water containing $1 \mu \mathrm{g}$ of copper(II). After adding $400 \mathrm{mg}$ of SDS, ultrafiltration was carried out with a 10000-Da cut-off membrane filter, and the permeate solution was analyzed by GFAAS. As is shown in Table 1, more than $96 \%$ of the copper(II) were adsorbed electrostatically at $\mathrm{pH} 2$ onto, or near, the micellar surface, which had a highly negative charge density. The recovery decreased with increasing the $\mathrm{pH}$ of the
Table 1 Collection of $1 \mu \mathrm{g}$ of copper(II) in $20 \mathrm{ml}$ of water by ultrafiltration $^{\mathrm{a}}$

\begin{tabular}{cccc}
\hline \multirow{2}{*}{ SDS added/mg } & \multicolumn{3}{c}{ Cu recovered, \% } \\
\cline { 2 - 4 } & $\mathrm{pH} 2$ & $\mathrm{pH} \mathrm{5}$ & $\mathrm{pH} \mathrm{7}$ \\
\hline 400 & $96,99,100$ & $71,75,79$ & 57 \\
0 & 3,5 & 3,10 & 47,58 \\
\hline
\end{tabular}

a. With a 10000-Da membrane filter.

solution, probably due to a decrease in the positive charge by the formation of hydroxocomplex or hydroxide. Direct ultrafiltration without SDS was also carried out for a comparison. In the absence of SDS, nearly all of the copper(II) passed through the membrane filter over the $\mathrm{pH}$ range of $2-5$. About half of the copper(II), however, was retained at $\mathrm{pH} 7$, probably due to the formation of colloidal copper(II) hydroxide.

The remaining solution on the membrane filter was viscous and contained large amounts of SDS. When a $10-\mu l$ aliquot of the solution was injected into a graphite cuvette, large background absorption (absorbance of ca. 0.9) occurred. Ashing at $900-1000^{\circ} \mathrm{C}$ decreased the signal intensity of copper without any reduction of the background. At higher temperatures, both the signal and the background decreased.

In addition to interference from the surfactants, the concentration factor obtained by MEUF was rather poor and the ultrafiltration membrane filter was expensive. Therefore, we proposed an alternative separation method of micelles, as described below.

\section{Adsorption of micelles on alumina particles}

Because the surfaces of alumina particles are positively charged in acidic solutions, they strongly adsorb anionic surfactants. ${ }^{9} 10$ This phenomenon was used for the separation of micelles from the mother liquor. In this experiment, copper(II) was preliminarily converted into the hydrophobic complex with APDC, because the collection based on electrostatic attraction was seriously affected by the solution $\mathrm{pH}$ and coexisting ions. The copper-APDC complex was trapped in the hydrophobic core of micelles and adsorbed on alumina by stirring. The separation of alumina particles from the solution was rapidly carried out by using a conventional porous disk (e.g., $36 \mu \mathrm{m}$ pore); hence, the sample volume could easily be increased.

Nanogram quantities of copper(II) in $100 \mathrm{ml}$ of water were completely recovered with $400 \mathrm{mg}$ of SDS and $3 \mathrm{~g}$ of alumina. The desorption of copper from the micelles was achieved with 4 mol $1^{-1}$ nitric acid, leaving SDS on alumina. The SDS accompanying copper was determined by the toluidine blue method and found to be less than $1 \mathrm{mg}$, which did not interfere with the determination at all.

\section{Application to water analysis}

The proposed method was applied to the determination of copper in certified reference water samples. To a 100-ml aliquot of the sample was added $2 \mathrm{ml}$ of an APDC solution at $\mathrm{pH} 2$. The preconcentration and determination were carried out as described in the Recommended procedure. As shown in Table 2, the analytical results were in good agreement with the certified values. The time required for a determination (including preconcentration and GFAAS) was less than $1 \mathrm{~h}$. Because APDC reacts with various heavy metals, ${ }^{11,12}$ combining the proposed preconcentration method with ICP-MS or ICPAES allows rapid and simple multielement determinations, 
Table 2 Determination of copper in reference water samples

\begin{tabular}{lcc}
\hline \multirow{2}{*}{ Sample $^{\mathrm{a}}$} & \multicolumn{2}{c}{$\mathrm{Cu}$ found $/ \mathrm{ng} \mathrm{ml}^{-1}$} \\
\cline { 2 - 3 } & Certified value & Analytical result $(n=4)$ \\
\hline $\begin{array}{l}\text { River water } \\
\text { (SLRS-3) }\end{array}$ & $1.35 \pm 0.07$ & $1.42 \pm 0.05$ \\
$\begin{array}{l}\text { Seawater } \\
\text { (CASS-3) }\end{array}$ & $0.517 \pm 0.062$ & $0.549 \pm 0.070$ \\
$\begin{array}{l}\text { Seawater } \\
\text { (NASS-5) }\end{array}$ & $0.297 \pm 0.046$ & $0.304 \pm 0.011$ \\
\hline
\end{tabular}

a. Salinity: $30.2 \%$ for CASS-3 and $30.5 \%$ for NASS-5.

which may provide useful and valuable information for environmental science and aquatic chemistry.

\section{References}

1. A. Mizuike, "Enrichment Techniques for Inorganic Trace Analysis”, 1983, Springer, Berlin.
2. Yu. A. Zolotov and N. M. Kuz'min, "Preconcentration of Trace Elements", 1990, Elsevier, Amsterdam.

3. R. O. Dunn, J. F. Scamehorn, and S. D. Christian, Sep. Sci. Technol., 1985, 20, 257.

4. J. F. Scamehorn, R. T. Ellington, S. D. Christian, B. W. Penney, R. O. Dunn, and S. N. Bhat, AIChE Symp. Ser., 1986, 82,48 .

5. B. Keskinler, U. Danis, A. Cakici, and G. Akay, Sep. Sci. Technol., 1997, 32, 1899.

6. S. Gelinas and M. E. Weber, Sep. Sci. Technol., 1998, 33, 1241.

7. B. R. Fillipi, L. W. Brant, J. F. Scamehorn, and S. D. Christian, J. Colloid Interface Sci., 1999, 213, 68.

8. M. Hiraide, T. Shima, and H. Kawaguchi, Anal. Sci., 1994, 10,505 .

9. K. T. Valsaraj, Sep. Sci. Technol., 1992, 27, 1633.

10. M. Hiraide, J. Iwasawa, S. Hiramatsu, and H. Kawaguchi, Anal. Sci., 1995, 11, 611.

11. O. G. Koch and G. A. Koch-Dedic, "Handbuch der Spurenanalyse", 1974, Teil 1, Springer, Berlin, 308.

12. E. B. Sandell and H. Onishi, "Photometric Determination of Traces of Metals: General Aspects", 1978, Wiley, New York, 529. 